\title{
Evidence of persistent seismo-volcanic activity at Marsili seamount
}

\author{
Antonino D'Alessandro, Giorgio Mangano, Giuseppe D'Anna
}

Istituto Nazionale di Geofisica e Vulcanologia, Centro Nazionale Terremoti, Rome, Italy

\author{
Article history \\ Received December 5, 2011; accepted April 25, 2012. \\ Subject classification: \\ Volcano monitoring, Marsili seamount, Seismo-volcano activity, OBS/H.
}

The Marsili submarine volcano is the largest European volcano, and it can be considered as the key to our understanding of the dynamics of the spreading and back-arc lithosphere formation in the Tyrrhenian sector [Marani et al. 2004, and references therein]. Despite its size, it is very difficult to monitor due to its geographical position [D'Alessandro et al. 2011], and it still remains little known.

In 2006, the Centro Nazionale Terremoti (National Earthquake Centre) of the Istituto Nazionale di Geofisica e Vulcanologia (INGV) deployed a broadband ocean-bottom seismometer with hydrophone (OBS/H) [Mangano et al. 2011] on the flat top of Marsili volcano, at a depth of ca. $790 \mathrm{~m}$. In only nine days, the instrument recorded ca. 800 seismovolcanic events [D'Alessandro et al. 2009]. This revealed the intense seismo-volcanic activity of Marsili volcano for the first time. However, the short duration of the experiment did not allow exhaustive characterization of the seismo-volcanic activities currently ongoing on the seamount.

For this reason, on February 14, 2010, another OBS/H was deployed at the same point for a long-term experiment (of 9 months). During this monitoring campaign, the submarine station recorded some thousands of local small-magnitude events. The entire dataset was classified on the basis of the time and frequency domain appearances according to Wasserman [2002]. Through this analysis, we recognized 589 volcano-tectonic type A (VT-A) events and 1,952 volcanotectonic type B (VT-B) events (Figure 1), with their local magnitudes measured according to Havskov et al. [2003].

The seismogram of a typical VT-A event is dominated by the $\mathrm{P}$ and $\mathrm{S}$ phases and by a short coda (Figure 1a). These events are characterized by $\mathrm{P}$ phases with impulsive and highamplitude onsets. The spectrogram shows broadband body phases with very high frequency and energy contents, extending up to $80 \mathrm{~Hz}$ (Figure 1c). The VT-A events that were recorded showed local magnitudes between 0.5 and 3.0, and duration times of between $40 \mathrm{~s}$ and $70 \mathrm{~s}$. For these earthquakes, the separation of the $\mathrm{P}$ and $\mathrm{S}$ waves is clear, and the $T_{S}-T_{P}$ is between $0.35 \mathrm{~s}$ and $0.55 \mathrm{~s}$. Their average recurrence time was about 2-3 events per week, with moderate variations through the observation period.

The VT-B events are characterized by $\mathrm{P}$ phases with emergent and low-amplitude onsets (Figure 1b). The waveforms do not show any clear S-wave arrivals, and they show a long coda (Figure 1b). The VT-B events have duration times of between $15 \mathrm{~s}$ and $40 \mathrm{~s}$, and local magnitudes between -0.5 and 1.5. Their spectrograms show a narrow frequency content (Figure 1d). The time distribution of VT-B occurrence shows periods of moderate activity (a few events per week) alternating with periods of intense activity (70 events per day). From Figure 1f, a time cyclic process is also clear, with an upward trend in the VT-B activity. An increase in the VT-B activity has often been reported for some active volcanoes before significant eruptions [Zobin 2011 and references therein].

These observations of VT swarms for the Marsili volcano strongly suggest that it is still active. Furthermore, it should not be ignored that potential volcanic eruptions might generate tsunamis along the nearby coastlines.

\section{References}

D'Alessandro, A., G. D'Anna, D. Luzio and G. Mangano (2009). The INGV's new OBS/H: analysis of the signals recorded at the Marsili submarine volcano, J. Volcanol. Geoth. Res., 183, 17-29; doi:10.1016/j.jvolgeores.2009.02.008.

D'Alessandro, A., D. Luzio, G. D'Anna and G. Mangano (2011). Seismic network evaluation through simulation: an application to the Italian National Seismic Network, B. Seismol. Soc. Am., 101, 1213-1232; doi: 10.1785/0120100066.

Havskov, J., J.A. Peña, J.M. Ibáñz, L. Ottermöller and C. Martínez-Arévalo (2003). Magnitude scales for very local earthquake. Application for Deception Island volcano (Antartica), J. Volcanol. Geoth. Res., 128, 115-133; doi:10.1016/S0377-0273(03)00250-6.

Mangano, G., A. D'Alessandro and G. D'Anna (2011). Longterm underwater monitoring of seismic areas: design of an ocean bottom seismometer with hydrophone and its performance evaluation, OCEANS, 2011 IEEE (Spain, June 6-9, 2011), ISBN: 978-1-4577-0086-6, pp. 1-9; doi:10.1109/ Oceans-Spain.2011.6003609. 

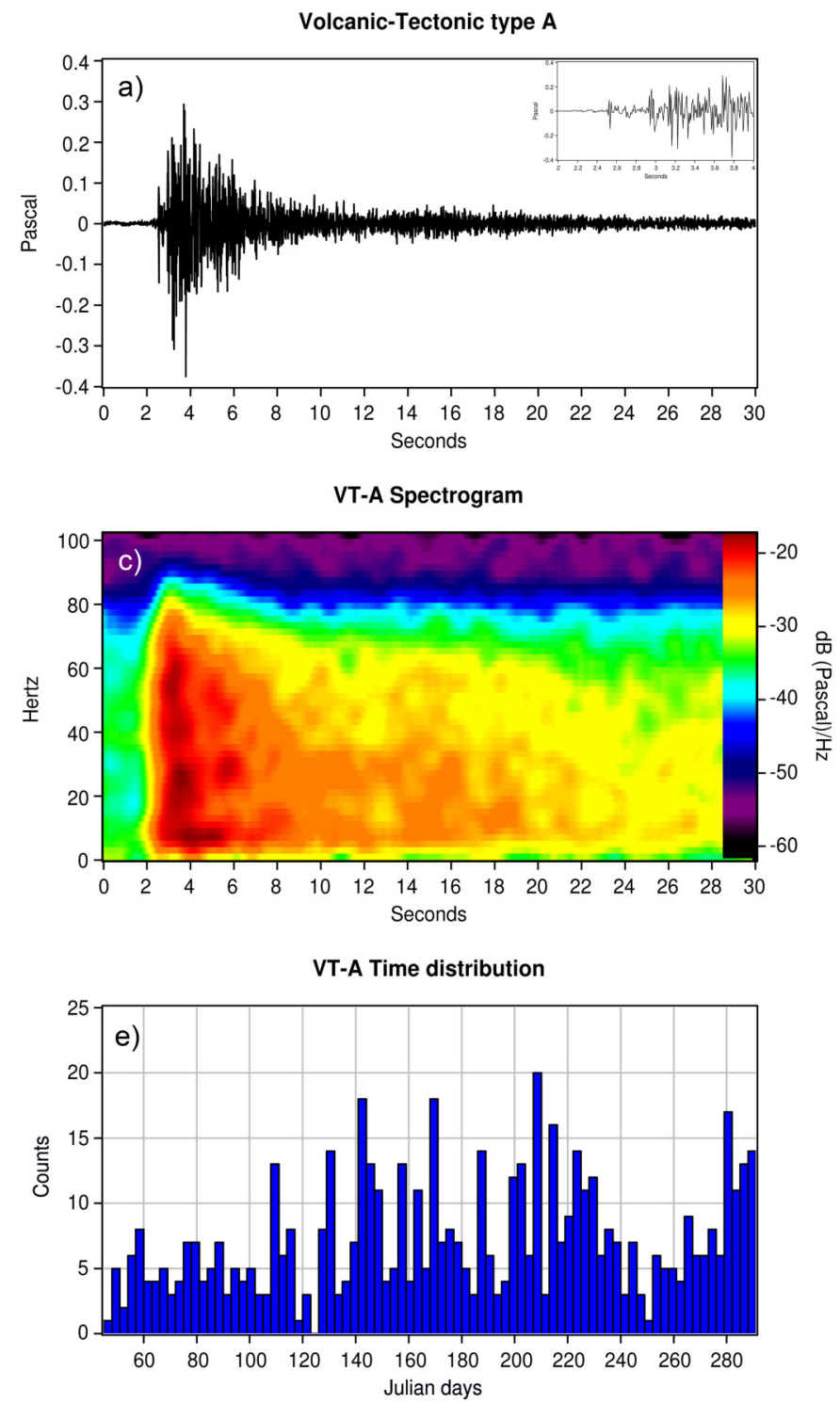
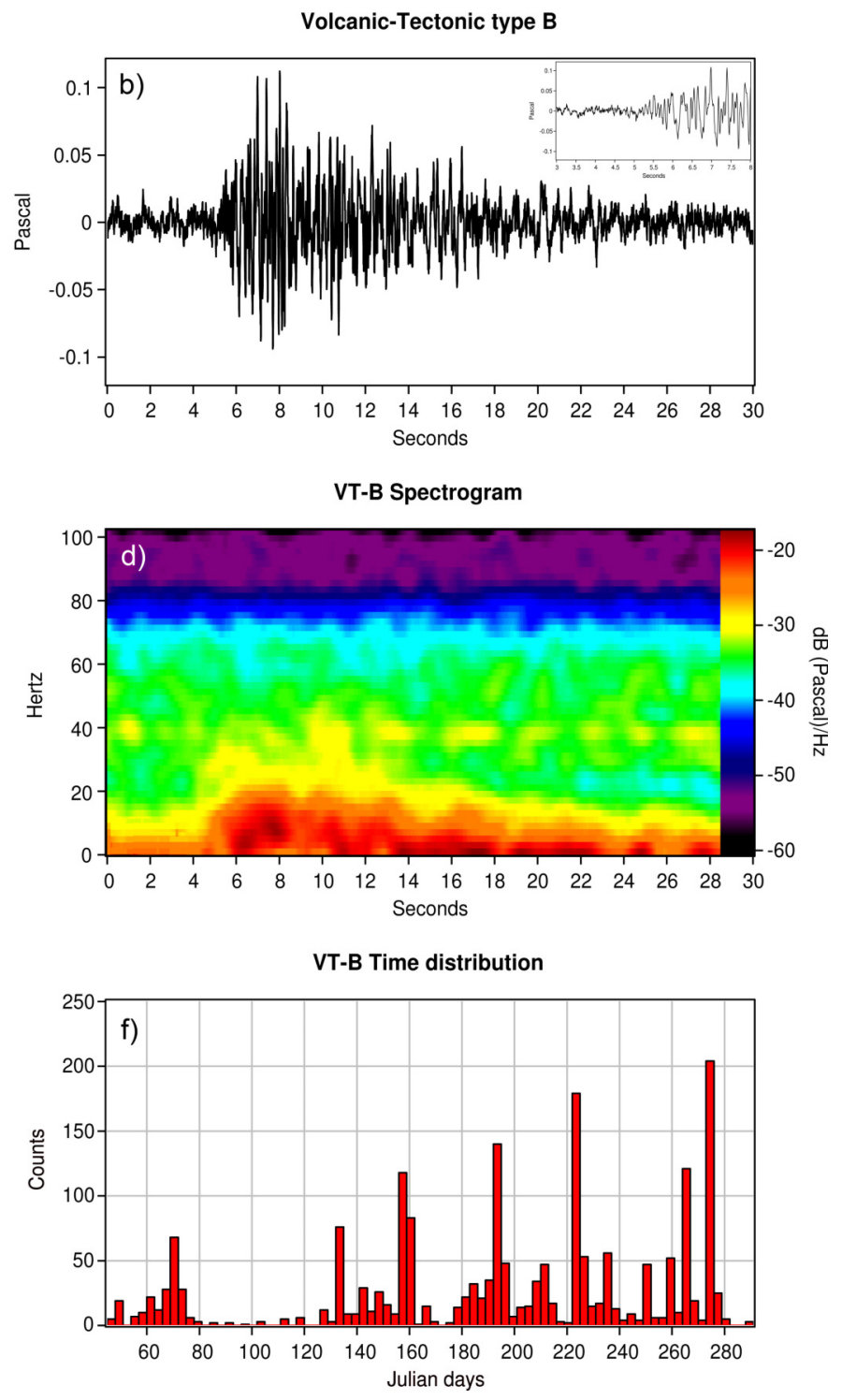

Figure 1. Waveforms (a, b), spectrograms (c, d), and time distributions (e, f) of the VT-A (a, c, e) and VT-B (b, d, f) events recorded on the Marsili volcano seamount during the 2010 monitoring campaign. Insets in (a) and (b): zoom in on the onset of the waveforms.

Marani, M.P., F. Gamberi and E. Bonatti (2004). From seafloor to deep mantle: architecture of the Tyrrhenian backarc basin, Series "Memorie descrittive della carta geologica d'Italia", vol. 64, 194 pp.

Wasserman, J. (2002). Volcano seismology, In: P. Bormann (ed.), IASPEI New Manual of Seismological Observatory Practice, vol. 1, GeoForschungsZentrum Potsdam, $42 \mathrm{pp}$.

Zobin, V.M. (2011). Introduction to Volcanic Seismology, 2nd edition, Elsevier, ISBN 9780444563750, 498 pp.
${ }^{\star}$ Corresponding author: Antonino D'Alessandro, Istituto Nazionale di Geofisica e Vulcanologia,

Centro Nazionale Terremoti, Rome, Italy; email: obslab@ingvit.
(C) 2012 by the Istituto Nazionale di Geofisica e Vulcanologia. All rights reserved. 